\title{
Present-day Horizontal Mobility in the Serbian Part of the Pannonian Basin; Inferences from the Geometric Analysis of Deformations
}

\author{
Zoran SUŠIĆ ${ }^{1}$, Marinko TOLJIĆ ${ }^{2}$, Vladimir BULATOVIĆ ${ }^{1}$, \\ Toša NINKOV ${ }^{1}$, and Uroš STOJADINOVIĆ ${ }^{2}$ \\ ${ }^{1}$ University of Novi Sad, Faculty of Technical Sciences, Novi Sad, Serbia; \\ e-mail: susic_zoran@yahoo.com (corresponding author) \\ ${ }^{2}$ University of Belgrade, Faculty of Mining and Geology, \\ Chair of Dynamic Geology, Belgrade, Serbia
}

\begin{abstract}
In tectonically complex environments, such as the Pannonian Basin surrounded by the Alps-Dinarides and Carpathians orogens, monitoring of recent deformations represents very challenging matter. Efficient quantification of active continental deformations demands the use of a multidisciplinary approach, including neotectonic, seismotectonic and geodetic methods. The present-day tectonic mobility in the Pannonian Basin is predominantly controlled by the northward movement of the Adria micro-plate, which has produced compressional stresses that were party accommodated by the Alps-Dinarides thrust belt and partly transferred towards its hinterland. Influence of thus induced stresses on the recent strain field, deformations and tectonic mobility in the southern segment of the Pannonian Basin has been investigated using GPS measurements of the horizontal mobility in the Vojvodina area (northern Serbia).
\end{abstract}

Key words: GPS measurements, Pannonian Basin, horizontal mobility, deformation analysis, active tectonics. 


\section{INTRODUCTION}

Present-day horizontal mobility of segments of the Earth lithosphere is expressed by the direction and intensity of recent strain field, intra-lithosphere stress distribution, existence of active tectonic structures, and rheological features of the lithosphere. In tectonically complex environments, such as the Pannonian Basin and its surrounding Carpathian and Alpine-Dinarides orogens, monitoring of recent deformations represents very challenging matter. Therefore, efficient quantification of active continental deformations demands use of a multidisciplinary approach that involves both neotectonic and seismotectonic methods. Moreover, development of modern GPS systems and their application in geodetic research enables better accuracy in quantification of recent movement of segments of the lithosphere. Application of geodetic methods in determination of geodynamic movements is based on studies of the temporal evolution of the reference system, which has been developed using physically stabilized points with determined positions in the three-dimensional coordinate system. Within the regional tectonic frame of the southeastern Europe, Serbia belongs to the area of bivergent orogen that was formed by the Cretaceous collision of the Adria micro-plate (as a part of African plate in that period) and the European plate (Bennett et al. 2008). Starting from the Lower Miocene, the Pannonian Basin has evolved in the domain of former suture between the two continental entities, which is recognized in the Upper Cretaceous flysch sediments of the Sava Zone (Pamić 2002, Schmid et al. 2008). The Miocene sediments of the Pannonian Basin, which represents classical example of a back-arc basin, cover the pre-Tertiary basement units of both Adriatic and European affinities (Horváth et al. 2006, Bada et al. 2007, Matenco and Radivojević 2012).

The predominant source of compressional stresses in the domain of the Alpine-Dinarides orogen is the northward movement of the Adria plate and its rotation in the counterclockwise direction (Straub 1996, Bada 1999, Bada et al. 1998, Marović et al. 2002, and references therein). This mode of motion of the Adria plate has established, starting from the Pliocene until recent times, compressional strain field oriented in the NE-SW direction (Gerner et al. 1999, Tesauro et al. 2006, Bada et al. 2007). Thus oriented field has reactivated already existing tectonic structures. In the central segment of the Dinarides, tectonically active are the reverse faults with the NW-SE direction (Fig. 1). Concurrently, in the southeastern and central part of the Pannonian Basin, strike-slip faults with the NE-SW and NW-SE direction (see Fig. 2) have been reactivated (Marović et al. 2002, 2007). Based on multiyear GPS/GNSS observations within the central European geodynamic network, the interpolated movement velocities of the northern segment of Adria microplate are in the interval between 2.5 and $3.5 \mathrm{~mm} / \mathrm{year}$ with the 


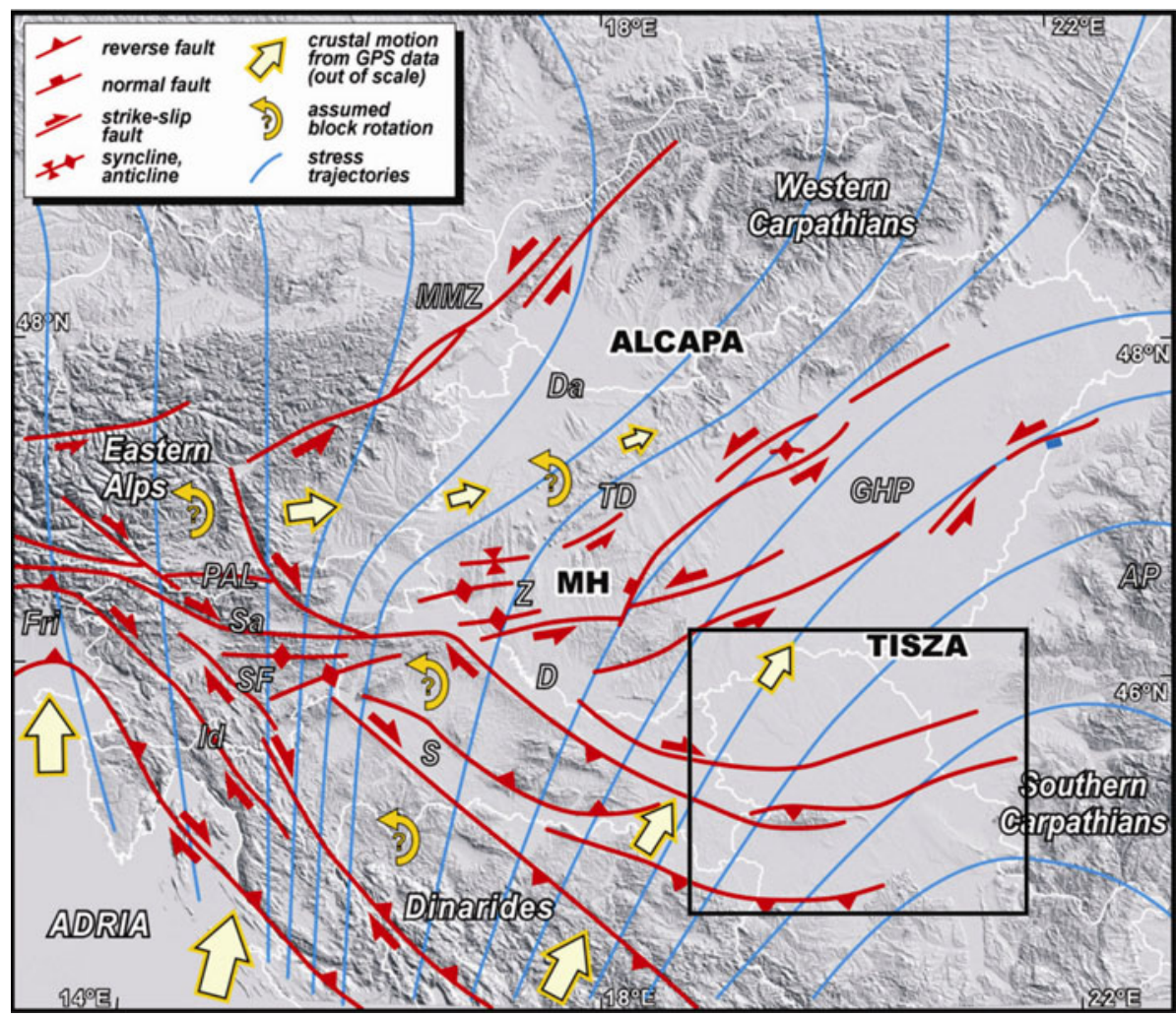

Fig. 1. The tectonic setting of the Serbian part of the Pannonian Basin (dark frame), with major active zones, and the trajectories of maximum horizontal stress directions (after Bada et al. 2007).

orientation towards the north-northeast, while for its southern segment they are between 3.5 and $5 \mathrm{~mm} /$ year with northeastern orientation (Grenerczy et al. 2005). Note that these data were obtained relative to the velocities minimization in the stabile segment of Europe. These results indicate that the motion of the northern segment of the Adria microplate towards north was accommodated by the deformation in the Southern Alps. Motion of the Adria plate is in the Dinarides area locally accommodated in the Dinarides thrust belt, while part of stress has been transferred to the northeastern hinterland of the orogen. In this manner, the intra-lithosphere stress distribution, recently produced along the Adriatic shore, has significant influence on the seismicity and tectonic mobility of the Dinarides northern and northeastern hinterland, as well as the area of the southern Pannonian Basin (Fig. 1).

Influence of this present-day transferred stresses on the tectonic structures and their kinematic features in the southern segments of the Pannonian 


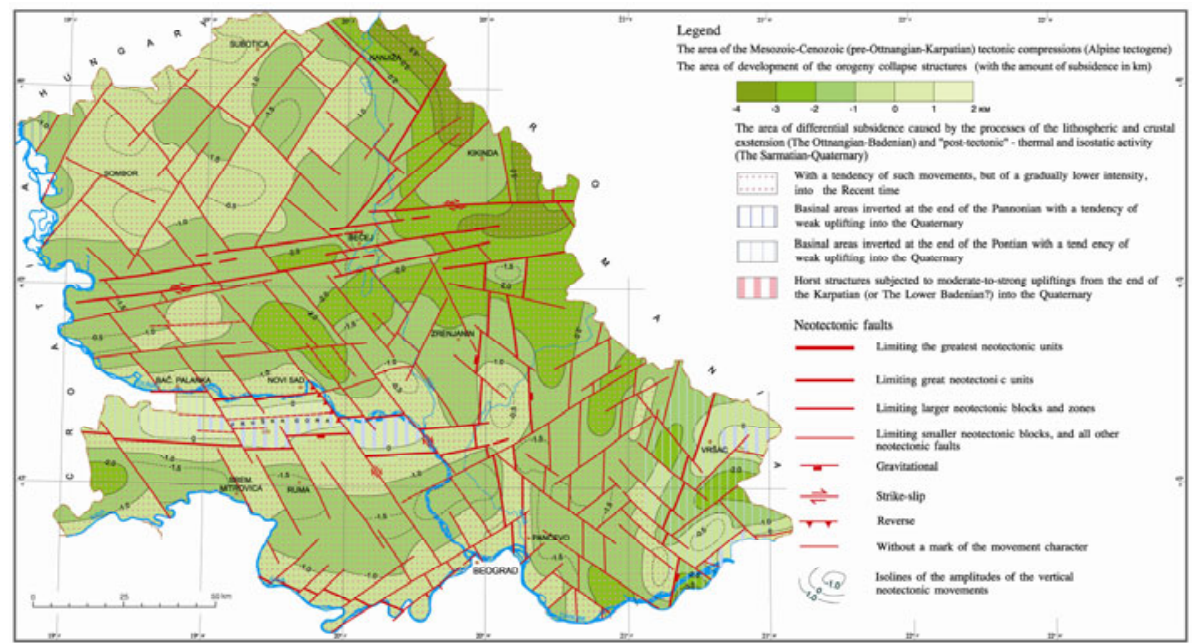

Fig. 2. Neotectonic map of Vojvodina (modified after Marović et al. 2007).

Basin so far has been considered only in context of tectonic synthesis and general kinematic patterns. Therefore, the main goal of this study was to obtain more detailed and accurate quantitative inferences concerning active continental deformations in the southern part of the Pannonian Basin. For that purpose, two successive geodetic measurement campaigns have been conducted to obtain the amounts of recent horizontal movements in this area. The results obtained were subsequently correlated with modern concepts concerning the tectonic architecture of the southern Pannonian Basin.

\section{REGIONAL TECTONIC SETTING OF THE PANNONIAN BASIN AND THE PROBLEM OVERVIEW}

The Pannonian Basin of central Europe includes parts of the territories of nine countries, whereby its central and largest segment is situated in Hungary (Fig. 1). The research area of the present study is located in the southern part of the Pannonian Basin, covering the territory of Vojvodina as the northern part of Republic of Serbia. In geographic coordinates, the research area is located between 44.7 and 46.2 degrees north latitude, and between 18.9 and 21.6 degrees east longitude.

In the geological context, the Pannonian Basin, surrounded by the Alps, Dinarides, and Carpathians orogens, has evolved as an extensional back-arc basin within the area of the complex zone of collision between the Adriatic and European plates (Horváth and Rumpler 1984).

The basin comprises two main lithospheric blocks separated by the midHungarian fault zone, the northern (ALCAPA) which has African affinity 
and the southern (TISZA) which has European affinity (Schmid et al. 2008 and other references here). The Early Miocene extension was produced by the roll-back of the subducted Carpathians lithosphere (Horváth 1993, Bada et al. 2007 and references therein). Extension was also accompanied by the eastward translation and complex rotations of the ALCAPA and the TiszaDacia units (Horváth et al. 2006, Schmid et al. 2008). This movement was driven by the push of the Adria plate, followed by the lateral extrusion of blocks from the Eastern Alps (Frisch et al. 1998, Jarosiński et al. 2006, 2011; Jarosiński 2012). According to all relevant investigations, lithospheric stretching during the extension has resulted in formation of basin setting characterized by the very thinned crust and high values of heat flux (Stegena et al. 1975, Szafian et al. 1997, Csontos 1995, Cloetingh et al. 2005). Its internal architecture is represented by very thick sedimentary infill, which in deepest parts of the basin can reach up to 7-8 $\mathrm{km}$ (Magyar et al. 2006). The Early and Middle Miocene basin evolution is characterized by the development of a series of asymmetric extensional detachment faults (Matenco and Radivojević 2012). In the southern part of the basin, faults showing two main orientations predominate and delimit the uplifted and subsided intrabasinal areas. East from the line Kikinda-Zrenjanin-Pančevo, major fault structures are mainly with N-S strike, while west from the aforementioned line regional structures with E-W strike prevail (Marović et al. 2007, Matenco and Radivojević 2012). Within the structures with E-W strike, besides faults that delimit the Fruška Gora morphostructure, the most significant are the faults that form segments of the Trans-Banat-Bačka Dislocation (TBBD). These faults cut the basin in Vrbas-Bečej area and sideways (Fig. 2, see also Marović et al. 2007). In the parts of the basin situated further to the east, faults with N-S orientation prevail, and among these Pančevo and Morava detachments with their northern and southern prolongations are most significant (Fig. 2). These detachment faults controlled opening of a series of asymmetric extensional sub-basins and depressions in the eastern segment of Serbian part of the Pannonian Basin (Matenco and Radivojević 2012). Post-rift thermal subsidence of the thinned Pannonian lithosphere represent main controlling factor of the Upper Miocene sedimentation (Cloetingh et al. 2006, Horváth et al. 2006, Cloetingh and Burov 2011). Pliocene to present-day tectonic evolution has been dominated by the compressional strain field (Horváth and Cloetingh 1996, Marović et al. 2002, Bada et al. 2007), which in the southern part of the Pannonian Basin is oriented in the NE-SW direction (Anderson and Jackson 1987, Bada et al. 2007). Compressional stress induced in the Adriatic-Dinaridic-Hellenidic convergence zone has resulted in the lithospheric folding of the thinned Pannonian lithosphere. This was accompanied by the horizontal and vertical mobility of large intra-basinal segments, as well as the basin periphery, final- 
ly resulting in the inversion of the basin (Horváth and Cloetingh 1996, Marović et. al. 2002, 2007; Horváth et al. 2006, Jarosiński et al. 2011). According to Grenerczy and Kenyeres (2006), around $2 \mathrm{~mm} / \mathrm{year}$ of recent shortening was calculated in the crustal segment located between the Adriatic shore and the Pannonian Basin. The very area of the Pannonian Basin undergoes shortening of around $1.5 \mathrm{~mm} /$ year, whereby in its northern segment shortening is E-W as the result of lateral extrusion of the Eastern Alpine units into the basin. On the other hand, the southern segments of the basin record NE-SW oriented shortening, which is due to Adria-plate indentation and transfer of stresses through the Dinarides into the Pannonian area (Bada et al. 2007). Recent compressional strain field is the predominant controlling factor of both vertical and horizontal mobility of lithospheric segments in the Pannonian domain and, in this regard, with its seismic activity. Seismic activity of the Pannonian Basin and its surrounding area has very variable intensity (Tóth et al. 2002). The boundary area between the Dinarides and Pannonian basin is characterized by medium yet frequent seismic activity, while the seismic activity of its southern part has low intensity (Marovic et al. 2002, 2007).

The main goal of this study was to determine the amounts of horizontal movements in the southern parts of the Pannonian basin, based on two consecutive GPS/GNSS measuring campaigns using physically stabilized points of the passive geodetic reference network, in roughly ten-year time interval. Hence, the purpose was to determine whether there are significant movements at the points of the passive reference network, covering the research area. Republic Geodetic Authority of Serbia has established a passive geodetic reference network for the purpose of developing spatial reference system. The completion of the first research campaign was carried out during 2002, and the second campaign during 2012. The two campaigns were carried out in order to assure the integrity and to survey the temporal evolution of the spatial coordinate system. Furthermore, thus developed geodetic model of lithospheric horizontal movements was correlated with recent geological studies that offer coherent model for the neotectonic activity in the Serbian part of the Pannonian Basin (Marović et al. 2002, 2007; Matenco and Radivojević 2012). This approach enables to discriminate main controlling factors of the present-day horizontal mobility in the Serbian part of the Pannonian Basin.

\section{DATA AND METHODS}

The projecting and realization of a passive reference geodetic network onto the regions under study has been carried out by the Republic Geodetic Authority of Serbia. The geodetic network was projected in the form of closed figures, most frequently quadrangles. In the measurements over points the 
GPS/GNSS method of fast statics with an average observation time interval of 90 min per point was applied. With regard to the fact that through these measurements the conditions for applying the static model of geometric deformation analysis had become satisfied, an idea was formed to compare the geodetic and geological studies in the given field of research.

In the geodetic deformation model one uses points of the passive reference network uniformly distributed over the region under study with a spatial resolution of about $10 \mathrm{~km}$. The vector processing within the network from the first measuring campaign was done by using commercial software. The vector processing in the first measuring campaign was done by using GPS Survey V.2.0 software, whereas for the second measuring campaign the vector processing was done by using Trimble Total Control V. 2.73 software. The definite processing was done by using precise ephemerides which had been taken by the IGS service. Also, through the ftp protocol with a provider, such as the Bern University, the ionosphere model for the time interval of the observations was taken. In the processing procedure, the tropospheric-refraction influence was taken into account where the Hopfield model without unknown parameters was used for the first campaign, whereas in the processing of the second campaign the Goad \& Goodman (Fixed Values) model was used. The vector processing was done within the closed polygon systems where only linearly independent vectors were taken into account. The quality of the measurements was verified if closing of the polygons was under the limit for allowed deviations of $2 \mathrm{ppm}$. The spatial coordinate differences subjected to processing are the input parameters for adjustment of measuring results by applying the least squares. The first step was the independent free adjustment of measuring epochs at the moments $t_{1}$ and $t_{2}$ aimed at eliminating gross and systematic errors. In order to avoid the datum influence on the global network congruence test from two epochs, the displacements and the corresponding variance covariance matrices are transformed into a new datum by applying the $\mathrm{S}$ transformation. The S-transformation is a very convenient tool for defining a subset of congruent network points.

The step concerning the preliminary identification of stable datum points within the time interval $\Delta_{t}=t_{2}-t_{1}$ was preceded by testing the homogeneity of measuring accuracy in both epochs. The stability of datum points was carried out by applying the Helmert transformation without changing the scale. These are points for which residual displacement vectors (congruency fitting deviations) do not exceed double estimation error values. For the purpose of confirming the preliminary stability of datum points one applies the single-point congruence test, on the basis of the following expression: 


$$
T_{j}=\frac{\hat{d}_{j}^{T} Q_{\hat{d}_{j}}^{-1} \hat{d}_{j}}{2 \hat{\sigma}_{0}^{2}} \sim F_{1-\alpha}(h, f),
$$

where $\hat{d}_{j}$ is the displacement between the two epochs with the correspondent cofactor matrix $Q_{\hat{d}_{j}}, h$ is the rank of $Q_{\hat{d}_{j}}, f$ is the number of degrees of freedom from both epochs, and $\hat{\sigma}_{0}^{2}$ is the unified variance factor.

\subsection{Deformation analysis}

The methodology of stable-points establishing is based on the common adjustment of the measured baseline vectors in both epochs on the basis of the conditionally stable points adopted a priori. This method has been developed at the University of Karlsruhe (Heck 1983). Karlsruhe method is based on independent adjustment of the first and the second epoch and also on their joint adjustment. In the first phase, measured values in the individual epochs are adjusted using the Least Squares Method (LSM). In the second phase, measured values in the first and the second epoch are jointly adjusted. Joint adjustment of the two epochs is being done under the assumption that the basic points are congruent in two epochs and that the network scale is the same in both epochs.

In the first phase, adjustment is made independently for all measured values in each epoch, using the indirect adjustment method:

$$
v_{i}=A \cdot x_{i}+f_{i}, \quad i=1,2, \ldots, k,
$$

where $k$ is the number of epochs. The network may be adjusted usually or with the minimum trace. From each individual adjustment, a square form $\Omega_{i}$ is being determined, and joint square form for all epochs is obtained by summing square forms of individual epochs' adjustments:

$$
\Omega_{0}=\sum_{i=1}^{k} \Omega_{i}=\sum_{i=1}^{k} v_{i}^{T} \cdot P_{i} \cdot v_{i}=v^{T} \cdot P \cdot v
$$

The total number of degrees of freedom $b$ is obtained by summing up the degrees of freedom $b_{i}\left(b_{i}=n_{i}-u_{i}\right)$ from individual epochs' adjustments.

During the second phase, measured values in zero and control measurement epoch are jointly adjusted. In joint adjustment of the two epochs, vector of unknown coordinates is divided into three sub-vectors:

$$
x^{T}=\left(z^{T}, x_{1}^{T}, x_{2}^{T}\right),
$$


where $z$ is the sub-vector of basic points assumed to be stable in both epochs, and $x_{1}^{T}, x_{2}^{T}$ are subvectors of construction points or points assumed to be unstable. From the joint adjustment, square form $\Omega_{z}$ is being determined, containing information on measurement errors and movements of unstable points. Joint adjustment square form $\Omega_{z}$ gets deducted from square form $\Omega_{0}$, which contains information about measurement errors only (Heck 1983, Mihailović and Aleksić 1994, 2008; Ambrožič 2004):

$$
\Omega_{h}=\Omega_{z}-\Omega_{0}=v_{z}^{T} \cdot P \cdot v_{z}-v^{T} \cdot P \cdot v .
$$

The new square form $\Omega_{h}$ contains only the information about unstable points' movement. The test statistics is (Heck 1983, Mihailović and Aleksić 1994, 2008; Ambrožič 2004):

$$
F=\frac{\Omega_{h} / f}{\Omega_{0} / b}=\frac{v_{z}^{T} \cdot P \cdot v_{z}-v^{T} \cdot P \cdot v}{v^{T} \cdot P \cdot v} \cdot \frac{b}{f},
$$

where $f=(k-1) n p_{0}-d, k$ is number of epochs, $n$ is the geodetic network dimension, $p_{0}$ is the number of conditionally stable points, and $d$ is the rank defect of matrix $A$.

If the $F \leq F_{f, b, 1-\alpha}$, zero hypothesis is not rejected, i.e., all of the points from conditionally stable points are indeed stable points; or else an alternative hypothesis is being accepted.

\subsubsection{Determining unstable points in the set of conditionally stable points}

With $F>F_{f, b, 1-\alpha}$, the set of conditionally stable points contains unstable points. It is necessary to determine such points. For that purpose, joint adjustments are repeated from which one conditionally stable point is being excluded successively. The adjustment providing the minimum value of the square form $\Omega_{z, \min }$ indicates that the point excluded from the adjustment is to be considered unstable. That point is definitely excluded from the set of conditionally stable points, and the entire procedure is repeated without it. The procedure is repeated iteratively, until the condition $F \leq F_{f, b, 1-\alpha}$ is met, and the points left in the set of conditionally stable points afterwards are considered stable.

\subsubsection{Localization of deformations}

Deformations are being localized for each point. The zero hypothesis assumes that the point $T_{j}$ did not move, while the alternative hypothesis assumes that the point $T_{j}$ did move. Zero $\left(H_{0}\right)$ and $\left(H_{a}\right)$ alternative hypotheses are being set (Heck 1983, Mihailović and Aleksić 1994, 2008; Ambrožič 2004): 


$$
H_{0}: E\left(\hat{d}_{j}\right)=0 \quad \text { against } \quad H_{a}: E\left(\hat{d}_{j}\right) \neq 0 .
$$

The test statistics reads:

$$
F_{j}=\frac{\theta_{j}^{2}}{\hat{\sigma}_{0}^{2}}=\frac{\hat{d}_{j}^{T} Q_{\hat{d}_{j}}^{-1} \hat{d}_{j}}{m \cdot \hat{\sigma}_{0}^{2}} \sim F_{m, f},
$$

where

$$
\begin{aligned}
& Q_{\hat{d}_{j}}=B^{T} \cdot Q_{\hat{x}} \cdot B=\left[\begin{array}{ll}
q_{\hat{y} \hat{y}} & q_{\hat{y} \hat{x}_{\hat{d}}} \\
q_{\hat{x} \hat{y}_{\hat{d}}} & q_{\hat{x} \hat{x}_{\hat{d}}}
\end{array}\right], \\
& \hat{d}_{j}=B^{T} \cdot \hat{x}=\left[\begin{array}{c}
\hat{y}_{2, j}-\hat{y}_{1, j} \\
\hat{x}_{2, j}-\hat{x}_{1, j}
\end{array}\right], \\
& \hat{\sigma}_{0}^{2}=\frac{b_{1} \cdot \hat{\sigma}_{0_{1}}^{2}+b_{2} \cdot \hat{\sigma}_{0_{2}}^{2}}{f}, f=b_{1}+b_{2}, \\
& m \text { - geodetic network dimension. }
\end{aligned}
$$

If the $F \leq F_{f, b, 1-\alpha}$, the zero hypothesis is not rejected; or else an alternative hypothesis is being accepted.

The presented statistical testing of hypothesis may also be interpreted geometrically. In the event of zero hypothesis $\left(H_{0}\right)$, formula 8 may be written as follows:

$$
\hat{d}_{j}^{T} Q_{\hat{d}_{j}}^{-1} \hat{d}_{j} \leq 2 \cdot \hat{\sigma}_{0}^{2} \cdot F_{2, f, 1-\alpha} .
$$

If we replace $\leq$ with $=$ in the formula 27 , the expression becomes an ellipse equation, which is identical to the relative error ellipse between the points $T_{1, j}$ and $T_{2, j}$ increased for the factor $\sqrt{2 \cdot F_{2, f, 1-\alpha}}$. Axes of the relative error ellipses are calculated using the formula:

$$
A_{i}=\sqrt{\hat{\sigma}_{0}^{2} \cdot 2 \cdot F_{2, f, 1-\alpha} \cdot \lambda_{i}}, \quad(i=1,2) .
$$

The deformation analysis using relative error ellipses can be presented graphically with ease (Figs. 1 and 2). Point movement vectors and increased relative error ellipses are drawn on the same sketch. The movement vector $\hat{d}_{j}$ starts at the point $T_{1, j}$ towards the point $T_{2, j}$, and the point $T_{2, j}$ is the center of ellipse. If the point $T_{1, j}$ is outside the ellipse surface, the zero hypothesis is being rejected, i.e., deformations in point $T_{1, j}$ are accepted with a certain probability. 


\subsection{Strain analysis}

The basic principles of strain analysis have been developed in the theory of elasticity and continuum mechanics, whereas in geodesy it has been applied in interpreting the deformations of the Earth's crust. The principles of strain analysis are applicable if the observed region or object is covered by the deformation model (geodetic network) which can be observed as a continuum deformation under load (Dermanis and Livieratos 1983, Caspary 2000). An advantage of the strain analysis in the geometric deformation analysis is its independence of the coordinate system chosen. The strain-tensor parameters are not affected by both translation and rotation of the coordinate system (Vaniček and Krakiwsky 1982, Dermanis and Livieratos 1983, Biagi and Dermanis 2006, Talich and Havrlant 2008). For the purpose of calculating the strain-tensor elements we use the on-line application of the Research Institute of Geodesy, Topography and Cartography from Prague (www.vugtk. $\mathrm{cz} / \sim$ deformace). The mathematical model has been described in the literature (Talich 2007, 2008, 2012). The algorithm for determining the strain-tensor elements can be presented through two steps:

The first step concerns the traditional task where one determines the displacements at all points of the deformation geodynamical model, i.e., of the passive reference network, over the research domain. An independent free adjustment of the passive reference network for both measuring epochs is carried out.

The second step concerns the determination of the deformation parameters by use of geometric analysis of continuum mechanics (strain analysis) in which the following two procedures are applied:

- A subdivision of the geodetic network into finite elements (triangles) and calculation of the strain-tensor parameters for each triangle (with formulating hypothesis on strain homogeneity for each triangle);

- Calculation of global-strain field for the research domain (with formulating hypothesis on strain homogeneity for the entire research domain).

The principle of geodetic methods applications is based on repeated measurement and comparation of results of individual stages of measurements. The obtained differences in positions of points represent their displacements (Talich 2007, 2008, 2012). The vector of point displacement is:

$$
d_{i}=\left(u_{1}, u_{2}, u_{3}\right)_{i}^{T}=x_{i}^{0}-x_{i}^{t},
$$

where $x_{i}^{0}\left(\right.$ resp. $\left.x_{i}^{t}\right)$ is vector of $P_{i}$ point coordinates of fundamental (resp. actual in $t$-time) stage. This vector may be expressed as a function of coordinates: 


$$
u=\left(u_{1}, u_{2}, u_{3}\right)^{T}=u(x)=\left(u_{1}(x), u_{2}(x), u_{3}(x)\right)^{T}=d, \quad x=(x, y, z)^{T} .
$$

The strain tensor in $P_{i}$ is defined as a gradient of the function in this point:

$$
E_{i}=\left[\begin{array}{lll}
e_{11} & e_{12} & e_{13} \\
e_{21} & e_{22} & e_{23} \\
e_{31} & e_{32} & e_{33}
\end{array}\right]_{i}=\operatorname{grad}\left(d_{i}\right)=\left[\begin{array}{lll}
\frac{\partial u_{1}}{\partial x} & \frac{\partial u_{1}}{\partial y} & \frac{\partial u_{1}}{\partial z} \\
\frac{\partial u_{2}}{\partial x} & \frac{\partial u_{2}}{\partial y} & \frac{\partial u_{2}}{\partial z} \\
\frac{\partial u_{3}}{\partial x} & \frac{\partial u_{3}}{\partial y} & \frac{\partial u_{3}}{\partial z}
\end{array}\right]_{i}
$$

In the displacement field, the next relation (Welsch 1983, Talich 2007, $2008,2012)$ is valid:

$$
d_{i}=E_{i} x_{i}+t,
$$

where $d_{i}$ is the displacement vector, $E_{i}$ is the displacement gradient, $x_{i}$ is the coordinate vector, and $t$ is the vector of translation elements.

The strain tensor may be divided into two parts:

$$
E_{i}=e_{i}+\Omega_{i}=\left(e_{j l}\right)_{i}+\left(\omega_{j l}\right)_{i}, \quad j, l=1,2,3,
$$

where $e_{i}$ is the symmetric tensor of deformation, and $\Omega_{i}$ is the antisymmetric tensor of rotation:

$$
\begin{gathered}
e_{j l}=\left(\varepsilon_{j l}+\varepsilon_{l j}\right) / 2, \\
\omega_{j l}=\left(\varepsilon_{j l}-\varepsilon_{l j}\right) / 2 . \\
e=\left[\begin{array}{lll}
e_{11} & e_{12} & e_{13} \\
e_{21} & e_{22} & e_{23} \\
e_{31} & e_{32} & e_{33}
\end{array}\right]_{i}\left[\begin{array}{ccc}
\varepsilon_{11} & \frac{1}{2}\left(\varepsilon_{12}+\varepsilon_{21}\right) & \frac{1}{2}\left(\varepsilon_{13}+\varepsilon_{31}\right) \\
\frac{1}{2}\left(\varepsilon_{12}+\varepsilon_{21}\right) & \varepsilon_{22} & \frac{1}{2}\left(\varepsilon_{23}+\varepsilon_{32}\right) \\
\frac{1}{2}\left(\varepsilon_{13}+\varepsilon_{31}\right) & \frac{1}{2}\left(\varepsilon_{23}+\varepsilon_{32}\right) & \varepsilon_{33}
\end{array}\right]_{i} \\
\Omega_{i}=\left[\begin{array}{cccc}
0 & \omega_{12} & \omega_{13} \\
-\omega_{12} & 0 & \omega_{23} \\
-\omega_{13} & -\omega_{23} & 0
\end{array}\right]_{i}=\left[\begin{array}{ccc}
0 & \frac{1}{2}\left(\varepsilon_{12}-\varepsilon_{21}\right) & \frac{1}{2}\left(\varepsilon_{13}+-\varepsilon_{31}\right) \\
-\frac{1}{2}\left(\varepsilon_{12}+-\varepsilon_{21}\right) & 0 & \frac{1}{2}\left(\varepsilon_{23}+-\varepsilon_{32}\right) \\
-\frac{1}{2}\left(\varepsilon_{13}+-\varepsilon_{31}\right) & -\frac{1}{2}\left(\varepsilon_{23}+-\varepsilon_{32}\right) & 0
\end{array}\right]_{i}
\end{gathered}
$$


One can write:

$$
d_{i}=\left(e_{i}+\Omega_{i}\right) x_{i}+t .
$$

The following deformation parameters for displacements projected to $\mathrm{XY}$ of the local coordinate system can be determined:
$\Delta=e_{11}+e_{22}$
total dilatation
$\gamma_{1}=e_{11}-e_{22}$
shear strains
$\gamma_{2}=2 e_{12}$
shear strains
$\gamma=\sqrt{\gamma_{1}^{2}+\gamma_{2}^{2}}$
total shear
$\varepsilon_{1}=\frac{1}{2}(\Delta+\gamma)$
maximum strain
$\varepsilon_{2}=\frac{1}{2}(\Delta-\gamma)$
minimum strain
$\varphi=\frac{1}{2} \arctan \left(\frac{\gamma_{2}}{\gamma_{1}}\right)$
direction of axis of maximum strain
$\psi=\varphi+\frac{1}{4} \pi, z a \omega_{12}>0$
direction of shear strain
$\psi=\varphi-\frac{1}{4} \pi, z a \omega_{12}<0$
direction of shear strain

With the aim of expressing the deformation parameters in the plane, the approximation of field of displacement vectors was applied, using polynomials, after solving necessary equations of the following type:

$$
u_{i}=A_{i}+B_{i} x+C_{i} y+D_{i} x y+E_{i} x^{2}+F_{i} y^{2}+\ldots
$$

where the values $e_{i j}$ were determined as the derivatives of values $u_{i}$ for respective coordinates. After full processing, the vectors of displacement are computed and displayed in a rectangular grid of arbitrary scale. Within the same grid, the deformation parameters for each intersection can be determined. The conventional approach of the geodetic deformation analysis is based on the datum determining for the passive reference network. With regard to the fact that the strain-tensor parameters are not affected by both translation and rotation of the coordinate system chosen (where the scale must be unchangeable between two measuring epochs), any errors due to the possibility of incorrect hypothesis concerning the stability of dynamical points are eliminated. It is important to note that it is not necessary to carry out any transformation of displacements from different coordinate systems, for instance ITRF $\Leftrightarrow$ ETRF. It is also unnecessary to reduce the displacements in ITRF by applying geodynamic models of movement of tectonic plates, such as APKIM2000 or NNR-NUVEL, with regard to the fact that 
here one deals with geodetic networks of regional character (Talich 2007, $2008,2012)$. On the basis of these facts we may conclude that real geodynamic activities are based on fixed deformation parameters contributing to a successful locating of faults within the framework of the research domain.

\subsection{Geostatistical analysis}

Geostatistic interpolation methods appear as a suitable way for generating the values of a spatial variable (in this case, magnitude or intensity of displacement) for a domain where there are no measurements, on the basis of the measuring data of the same variable at locations given a priori (positions of points of the deformation geodynamic model). The spatial estimation of the displacement magnitude for the entire domain is carried out by using the geostatistic method known as Ordinary Kriging. Assuming the linearity of the displacement magnitude within the time interval $\Delta_{t}=t_{2}-t_{1}$, the spatial estimation of the displacement magnitude, as the difference of the position estimates from two measuring epochs ( $\mathrm{mm} /$ year) by applying the geostatistic interpolation method Ordinary Kriging, is carried out. The Kriging interpolation offers a possibility of generalization and prediction of displacementspeed trends, as well as of removing the local effects which are not due to the tectonic movements. In the case of Ordinary Kriging one assumes the quasi stationary state, where the function increments are stationary, but not the function itself. The method sensitivity depends on the input parameters characterizing modelling phases. The Ordinary Kriging method is based on the spatial analysis of model errors. Two primary indicators are the variogram and covariogram (covariance) used in the random field characterization assuming the spatial correlation between the predicted results. The variogram describes the variance variations between the elements in the framework of the field, whereas the covariogram describes the correlation between the given data (Webster and Oliver 2007). After calculating the experimental variogram the modelling is performed by applying the Gaussian variogram model. Spatial interpolation parameter dilatation in the subject area is performed by applying Inverse Distance Weighting method. Inverse Distance Weighting is a deterministic, nonlinear interpolation technique that uses a weighted average of the attribute (i.e., phenomenon) values from nearby sample points to estimate the magnitude of that attribute at non-sampled locations. The weight a particular point is assigned in the averaging calculation depends upon the sampled point's distance to the non-sampled location.

\section{RESULTS}

The average positional accuracy for the estimated coordinates is 6.4 and $8.0 \mathrm{~mm}$ in the cases of the first and second measuring epochs, respectively. 
A homogeneous accuracy of measurements is achieved for both measuring epochs. Using expression 6 we calculate the test statistics $(F=1.56)$ which obeys Fisher's central distribution $\left(<F_{12 ; 1341 ; 0.95}=1.76\right)$. In this way, the hypothesis on stability of selected datum points is confirmed.

The horizontal displacements of the relative network points, calculated as changes of coordinates acquired from GPS measurements, were determined in a local, topocentric system defined by a reciprocally stable reference points (Cacoń et al. 2004). The displacement vectors and relative confidence ellipses are determined for a probability of $95 \%$. The average values of relative confidence ellipses are 15.8 and $12.2 \mathrm{~mm}$ in the semimajor and semiminor axes, respectively. In this manner, in Fig. 3 the areas of significant movements are distinguished, including the area north of Fruška Go$\mathrm{ra}$, the area between Kikinda and Kanjiža, the domain east from Zrenjanin, and the area of Vršac Mts. The results obtained had to be correlated with the available information on the tectonic architecture of the area, in order to explain the variability in orientation and magnitude of vectors of displacement (Fig. 3). The map showing the trends of blocks movements within the southern segment of Pannonian Basin was generated by the interpolation of displacement vectors (Fig. 4). This yielded more coherent image of movement

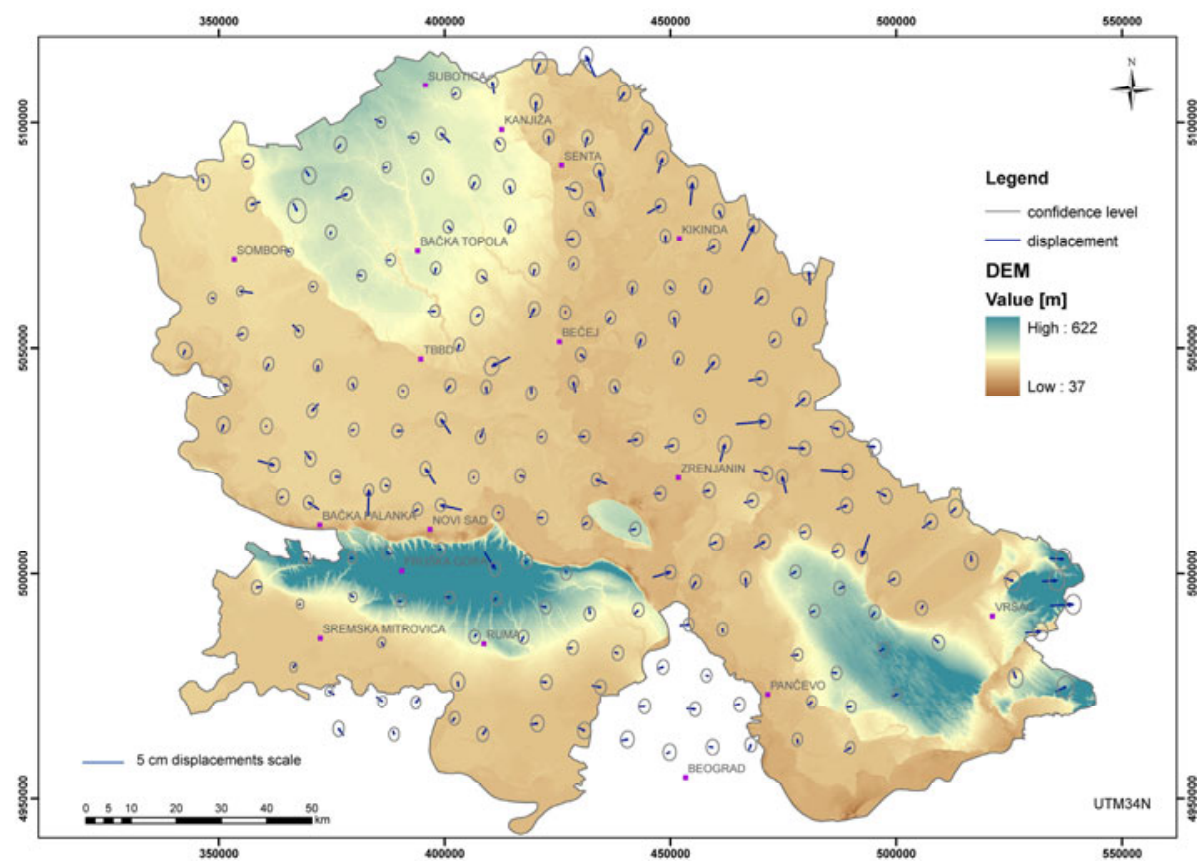

Fig. 3. Displacement vectors with relative confidence ellipses $(1-\alpha=0.95)$; vectors are shown in the DEM of the Vojvodina area. 


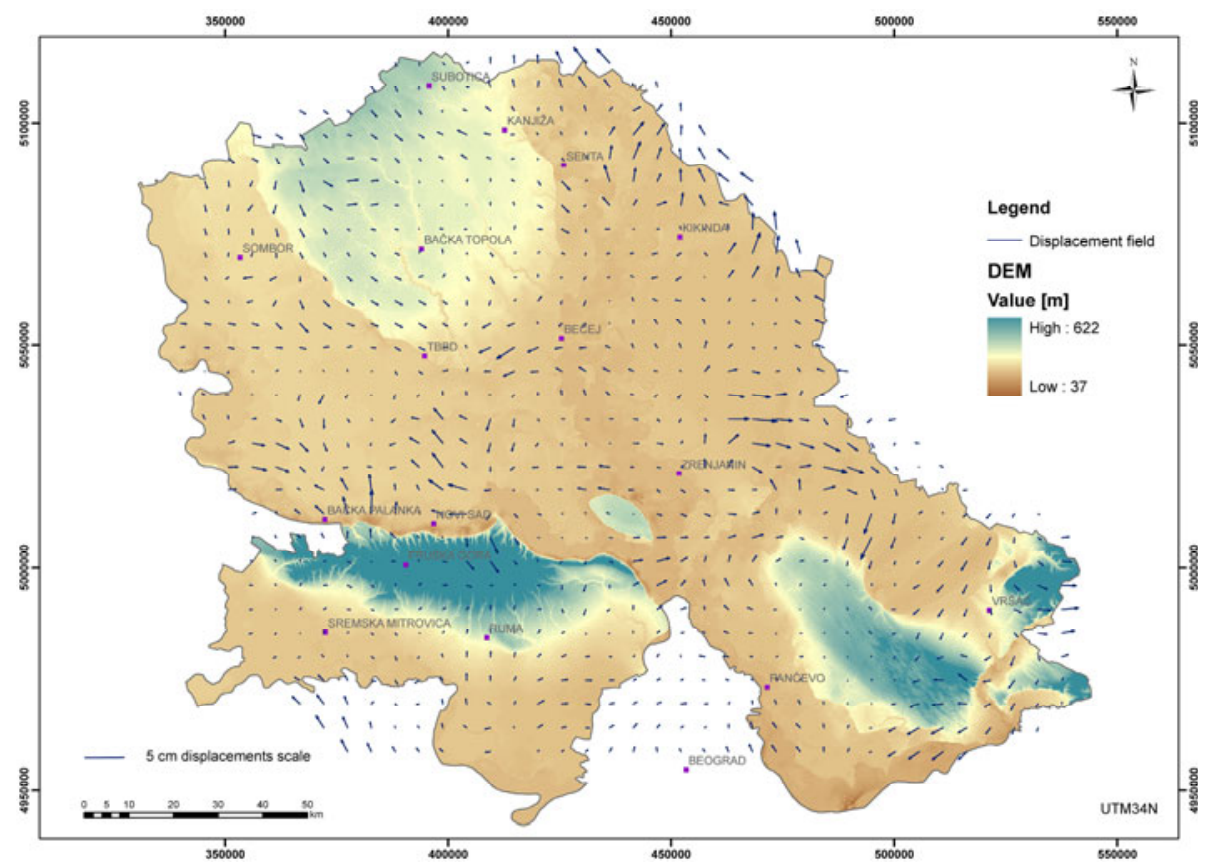

Fig. 4. Displacement field (www.vugtk.cz/ deformace); the interpolated amounts of movement are shown in the DEM of Vojvodina area.

of major blocks that comprise the southern Pannonian basement. The field of displacement is indicating that the southern basinal segments are shifting towards east.

The block located north from Fruška Gora is moving towards the north, the domain between Kanjiža and Kikinda is moving towards the northeast, while similar trend of movement can also be recognized in the central parts of the basin. The entire segment located east of the Kikinda-ZrenjaninPančevo line is moving towards the east. On the basis of the displacement intensities obtained over an approximately ten-year time interval the magnitudes of displacements are calculated in units [mm/year]. By using the geostatistic-interpolation Ordinary Kriging method the magnitudes of displacements are predicted over the entire research domain and, in this way, their continuity is simulated (Fig. 5). The minimum values were obtained in the western and southeastern segments of the research area, and the maximum values in the northeastern and eastern parts.

Based on detection of a certain number of points of a significant magnitude and divergent displacement azimuths, not logical from the aspect of understanding geodynamic activities, we start the cleaning of the network from the data indicating "false" measurements or unstable stations. 


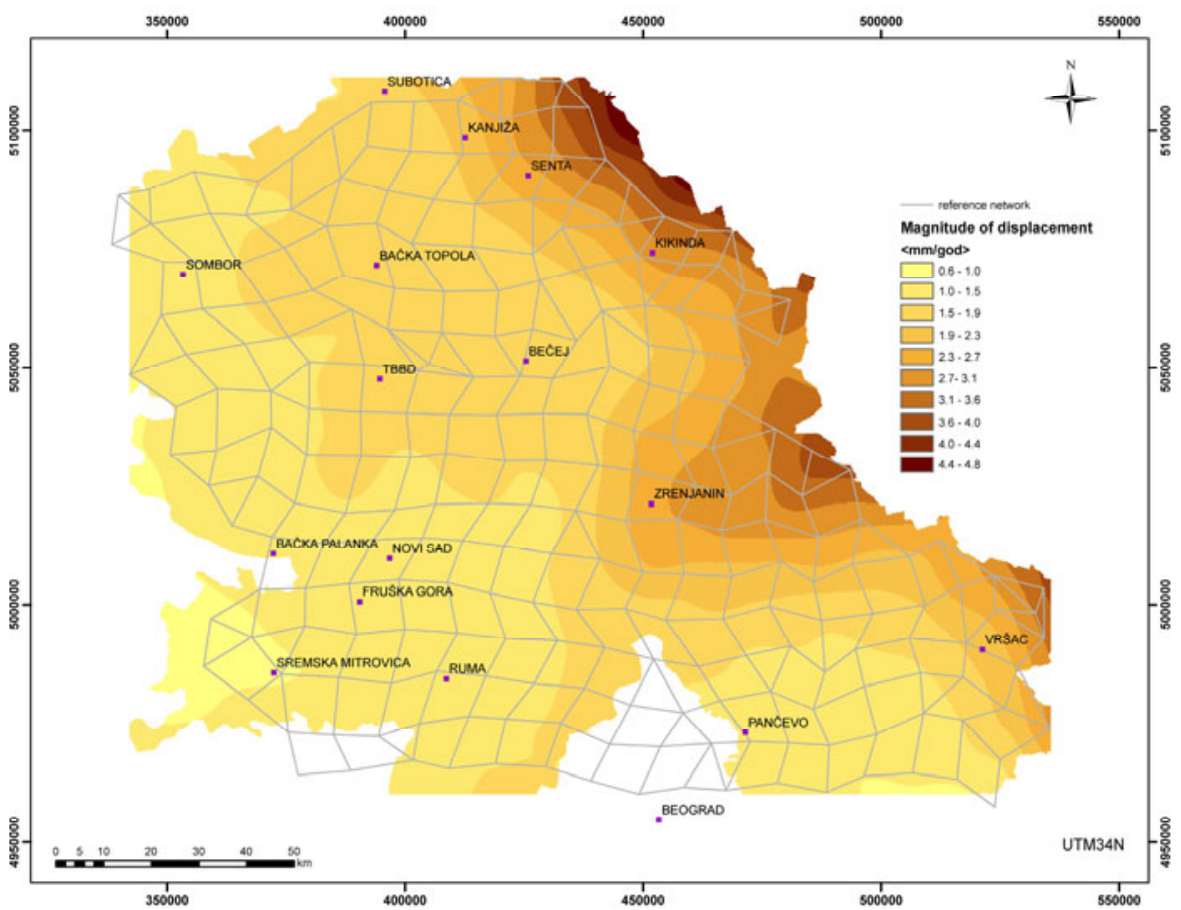

Fig. 5. Spatial distribution of displacement magnitudes predicted by using the Ordinary Kriging method with passive-geodetic-network configuration.

The cleaning procedure of the network is carried out in accordance to the methodology presented in the references (Bogusz et al. 2013, Araszkiewicz and Jarosiński 2013, Bogusz and Figurski 2012). A total of excluded "doubtful points" is seven so that we have 212 remaining points included in the analysis. The scope of the study is divided into final elements (triangles) and on this basis the strain tensor parameters are determined for each element. The network is constructed of triangles by using Delaunay triangulation method (Fig. 6).

On the basis of points displacement changes of geodetic network, that are implemented by their repeated survey, parameters of discretely expressed field of displacements are calculated (displacements interpolated into grid, Fig. 4), and further parameters of discretely expressed field of displacements are calculated, characterized by strain tensor (of extension and contraction, Fig. 8). The whole calculation is based on the theory of mechanics of continuum (Szostak-Chrzanowski et al. 2006, Talich 2007).

On the basis of the spatial distribution of maximal and linear deformations it can be seen that the northeastern area between Senta and Kikinda is characterized by a significant accumulation of contraction character strain, 

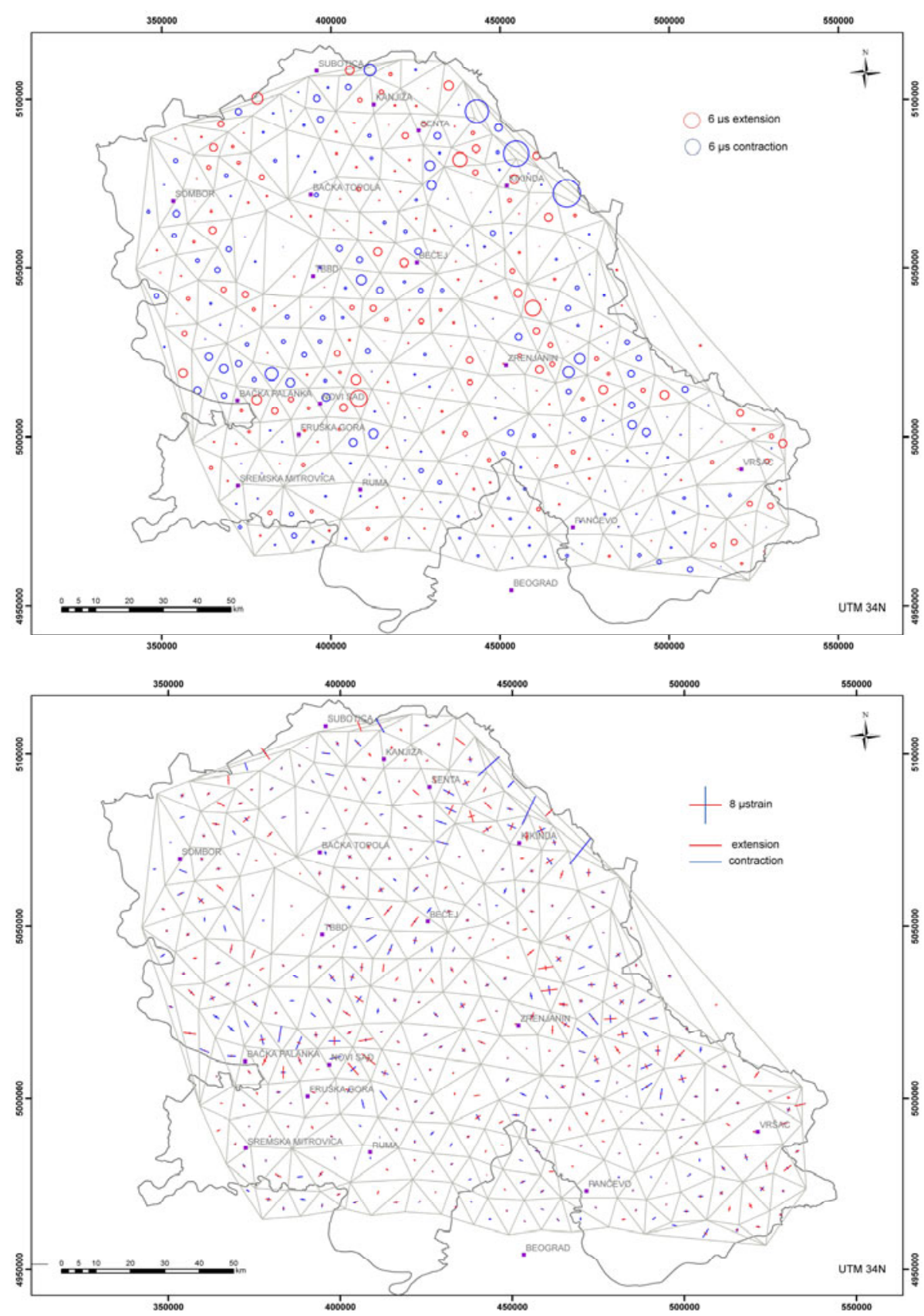

Fig. 6. Spatial distribution of extension and contraction (above) and principal strain parameters (below) of the triangles in the area of research. 
on the average greater than $2 \mu$ s when the interpolation field within the grid with dominant maximum strain directions from southwest towards northeast is considered (Table 1).

Table 1

The significant values of deformation parameters in interpolation grid in units of $[\mu \mathrm{s}]$

\begin{tabular}{|c|c|c|c|c|c|c|c|l|}
\hline $\mathrm{Y}[\mathrm{m}]$ & $\mathrm{X}[\mathrm{m}]$ & $\varepsilon_{1}$ & $\varepsilon_{2}$ & $m_{\varepsilon_{1}}$ & $m_{\varepsilon_{2}}$ & $\Delta$ & $\gamma$ & \multicolumn{1}{|c|}{ Area } \\
\hline 368851 & 5026087 & -0.66 & -1.50 & 0.28 & 0.23 & -2.16 & 0.83 & $\begin{array}{l}\text { Bačka } \\
\text { Palanka }\end{array}$ \\
\hline 398851 & 5046087 & -0.22 & -0.99 & 0.24 & 0.21 & -1.20 & 0.77 & TBBD \\
\hline 458851 & 5096087 & -0.16 & -1.73 & 0.39 & 0.32 & -1.89 & 1.57 & Senta \\
\hline 408851 & 5016087 & 1.66 & -0.16 & 0.21 & 0.21 & 1.50 & 1.81 & $\begin{array}{l}\text { Fruška } \\
\text { Gore }\end{array}$ \\
\hline 448851 & 5076087 & 1.30 & -0.02 & 0.24 & 0.19 & 1.28 & 1.32 & Kikinda \\
\hline 458851 & 5046087 & 1.65 & 0.09 & 0.19 & 0.28 & 1.74 & 1.55 & Zrenjanin \\
\hline 528851 & 5006087 & 1.32 & 0.43 & 0.48 & 0.63 & 1.75 & 0.89 & Vršac \\
\hline
\end{tabular}

Explanations: $m_{\varepsilon_{1}}$ and $m_{\varepsilon_{2}}$ respresent accuracy of $\varepsilon_{1}$ and $\varepsilon_{2}$, respectively.

Significant extension values are characteristic for the area of the north and northeast slopes of Fruška Gora, which are within an interval of from 0.5 to $1.5 \mu \mathrm{s}$. Another characteristic area concerns the region of the Vršac Mountains where the strain accumulation attains $1.2 \mu$ s (Figs. 7 and 8).

Interpolation algorithms appear as a suitable tool to generate the values of a given variable (in this case, the area is variable, i.e., dilatation) over the area for which no measurements have been realized, on the basis of the measuring data for the same variable on the places determined a priori (positions of points of geodynamic deformation model). The spatial interpolation of dilatation parameters is carried out by applying the Inverse Distance Weighting method. This interpolation is aimed at attempting to present a relatively uniform deformation picture on the subject territory (Fig. 7).

Strain parameters in Table 1 show that significant values of strain accumulation were around the area north of Fruška Gora, the area between Kikinda and Kanjiža, the domain east from Zrenjanin, and the area of Vršac Mts. 


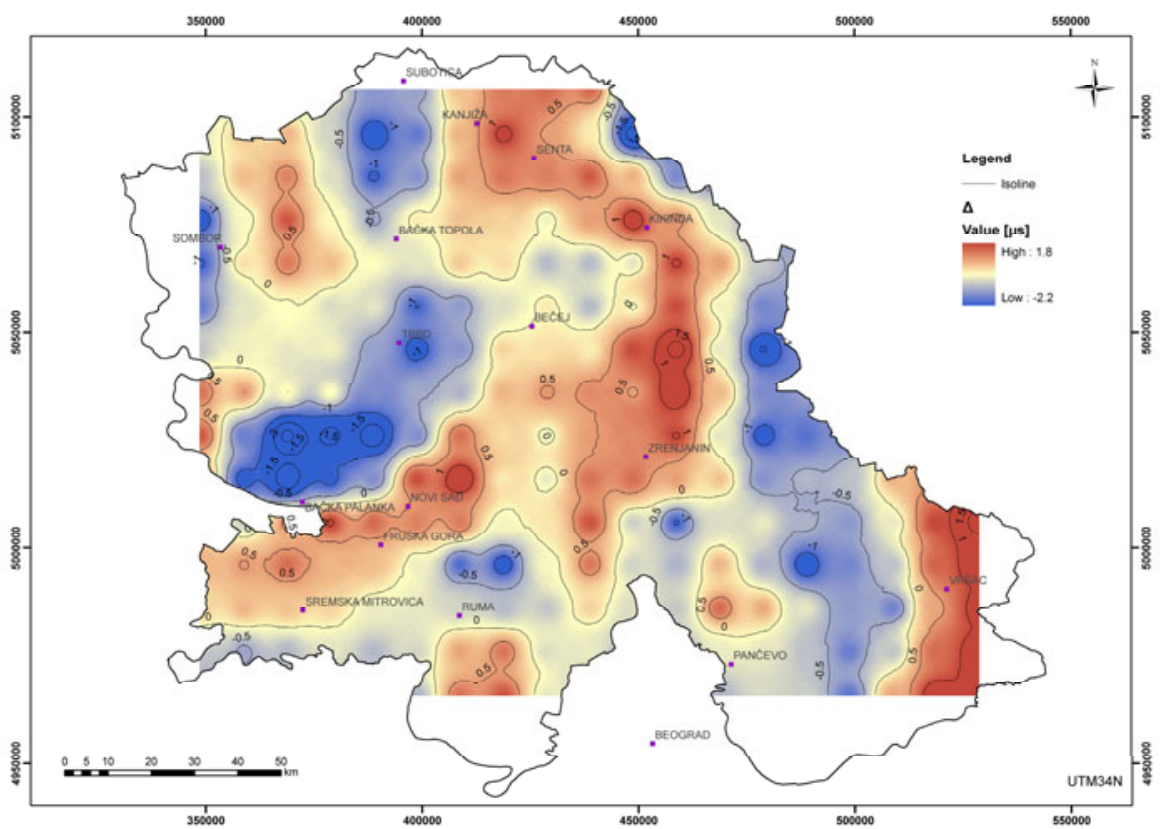

Fig. 7. Map of predicted changes on the surface based on parameters of dilatation in the grid by applying of Inverse Distance Method.

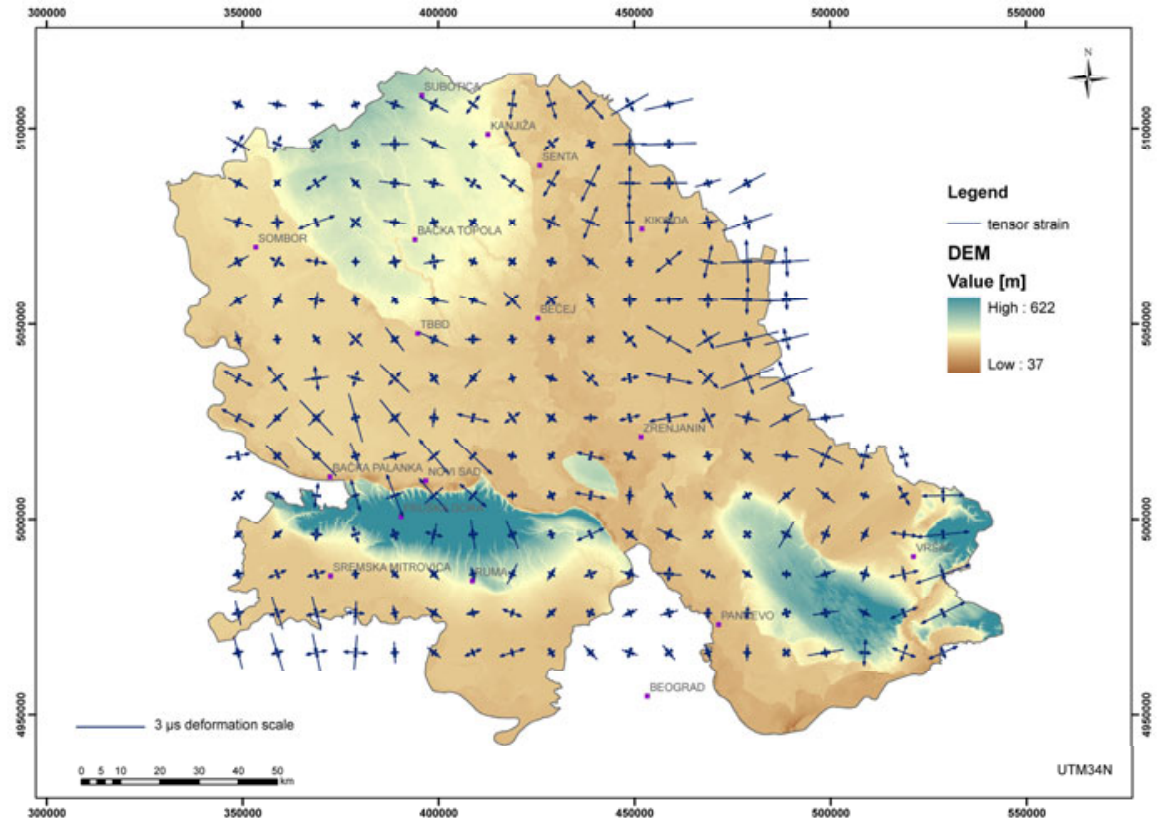

Fig. 8. Graphical interpretation of calculated strain-tensor elements within grid of $10 \mathrm{~km}$ (www.vugtk.cz/ deformace). 


\section{DISCUSSION}

Stress that was produced along the Adriatic shore and transferred through the Dinarides into the Pannonian Basin is interpreted to have its maximum axis oriented in NE-SW direction in southern basinal segment (Bada et al. 2007, Grenerczy and Kenyeres 2006). Hence, it would be expected that a rather uniform motion of a homogeneous style occurs in the aforementioned direction. However, reconstructed displacements based on the data obtained in this study (Fig. 3) apparently indicate very non-coherent condition. The displacement vectors given in function of presenting real amounts and orientations of movement are very scattered. The results of the deformation analysis indicate existence of several segments in the southern Pannonian Basin that expose different types of deformation. Recent mobility is, therefore, directly associated with already existing tectonic structures, which were in major part inherited from Neogene phase of extension. The reconstructed neo-alpine structure of the Pannonian Basin (Fig. 2, after Marović et al. 2007) indicates that the basin has very complex tectonic architecture. The basin is characterized by the presence of a number of positive and negative morphostructures, delimited by a series of tectonically active fault zones. Major faults, being part of already defined tectonic setting, represent the structures with strong influence on the stress distribution and deformations. Hence, these faults influence both the type and the amounts of movements of different crustal segments. The presence and recent activity of the faults oriented in E-W and $\mathrm{N}-\mathrm{S}$ directions is evident from the distribution of fields of contraction and tension and principal stain parameters, where the change from one dominant regime to another is also marking the active faults positions (Figs. 2 and 8). Therefore, the priority over analyzing small areas that expose local anomalies is to analyze each regional block separately, since these general trends appear to be much more instructive.

In the Fruška Gora area, the exhumation of the metamorphic core of the mountains occurred along the major faults with E-W orientation (Toljić et al. 2013). The displacement vectors in the area north of the mountains are oriented towards the north and northwest (Figs. 3 and 4). This type of movement is due to activity of both recent normal faults along the northern flanks of the Fruška Gora Mts. and right reverse movements along the faults oriented NW-SE (Fig. 2). Hence, the existing structures, recognized also during earlier geological and geophysical investigations (Marović et al. 2002, 2007; Matenco and Radivojević 2012, Toljić et al. 2013) have been reactivated.

In the central parts of the research area, major structure named TransBanat-Bačka-Dislocation (TBBD) is oriented roughly in the E-W direction, thus separating this segment of the basin in northern and southern part. In the Quarternary, TBBD has been reactivated as a left strike-slip fault (Marović 
et al. 2007). Such kinematic pattern is in agreement with the N-S oriented trans-tension that was documented in this domain (Fig. 2).

In the eastern part of the research area prevalent are the faults oriented in the N-S direction. Complex structural setting comprised of a series of subbasinal depressions and highs is controlled by the two major detachment faults zones. Along these asymmetric faults, the eastern segment of the southern Pannonian Basin was opened during Miocene phase of extension (Matenco and Radivojević 2012). The western rim of the Pančevo Depression is delimited by Pančevo detachment, whereby along its northern prolongation is connected with the Mako Depression through a series of subdepressions and faults. The second major Morava detachment is located further east, representing the western boundary of the Drmno Depression. In recent times, eastward movement of basin segments located east from the Pančevo detachment has been noted. In the southeastern periphery of the Pannonian Basin, significant displacement towards east were reconstructed, with the extension axis oriented E-W (north from the town of Vršac) and ENE-WSW (south from Vršac, Fig. 8). Interestingly, the entire domain is under significant extension, whereby the area south from the Vršac Mts. is with significant amounts of total dilatation (Fig. 7).

In the basin segment located between the towns of Kikinda and Kanjiža, faults change their orientation, predominantly becoming NW-SE oriented. The block located northeast from these structures is significantly displaced towards the northeast, while the southwestern block is moving towards the southwest. The reconstructed strain field (Fig. 8) in the Kanjiža area is characterized by N-S oriented extension. Recent dynamics of this segment should be interpreted in wider context of the evolution of Mako depression, which is in its major part located in the territory of Hungary. The average thickness of Tertiary sediments in the Mako depression is between 7 and $8 \mathrm{~km}$ that corresponds to the strong subsidence in this area during Neogene times. Maintained trend of the Quaternary subsidence in this depression is recognized in the general migration of its southeastern periphery to the north. Furthermore, strain analysis recorded recent contraction in the area northeast from the town of Kikinda (Fig. 7) that can be attributed to the interplay of a relatively shallow rigid crustal basement and the recent regional strain field. Hypsometrically elevated morphostructures, as shallowly positioned segments of Pannonian basement, act like rigid bodies, thus producing local E-W to NE-SW oriented contraction in the southeastern segments of Mako depression.

The results of the displacement magnitudes reconstruction appear to be very interesting (Fig. 5). The minimum amounts of displacement are in the western segment of the studied area, as well as in the domain located east from the town of Pančevo. The displacement magnitudes are uniformly in- 
creasing going from west to east. However, it should be expected that the western and not the eastern segments of the southern Pannonian have larger magnitudes of horizontal displacement, with the fact that the entire basin is under compression deriving from the Dinarides located further west. Therefore, the change in predicted trend can be, once more, associated with the inherited tectonic structures. It is evident that the most significant eastward displacements are located east from the main detachment zones with N-S orientation. During the latest Neogene stage of evolution, these prominent crustal-scale structures were formed as a result of the final phases of the oceanic slab roll-back in the Carpathians area. The extension terminated following the final moments of the oceanic slab detachment (Matenco and Radivojević 2012). Apparently, the patterns of dilatation indicate that segment of the detached oceanic lithosphere in the Southern Carpathians (Martin and Wenzel 2006) can still influence the strain field, kinematics and the deformations in the eastern parts of the southern Pannonian Basin.

Strain tensors interpretation in Figs. 6 and 8 is presenting model of the recent strain field in the southern Pannonian Basin. The general trends in spatial distribution of the axes of contraction and tension are of the biggest significance. The two typical spatial relations patterns can be recognized. First are the segments where the intensity of shortening and tensional deformations is small and uniform, and second are segments with the significantly higher values of shortening or tensional strain component. The entire domain analyzed is under the contraction generally oriented in the NE-SW direction, in agreement with previous reconstructions of the recent strain field (Bada et al. 2007). Trend of gradual rotation of the axis of compression towards the direction E-W is noticeable. East from the Kanjiža-Kikinda-ZrenjaninPančevo line, the contraction axes have similar orientation with the direction NE-SW. Interestingly, the extension oriented in NE-SW and E-W direction is present in the areas of Senta, Zrenjanin, and Vršac. It appears that the eastern and southeastern parts of the southern Pannonian realm have been deformed in the strain field dominated by the tension oriented in directions E-W and NE-SW. Such strain field features may indicate the ongoing influence of extension, which is potentially produced by the presence of the remnants of the detached oceanic slab recognized in the vicinity of southeastern periphery of the basin.

\section{CONCLUSIONS}

Recent regional strain field and the mobility of crustal segments in the Pannonian basin domain are influenced by complex interaction between the Adria micro-plate, Alps-Dinarides and Carpathians. The NE-oriented indentation of Adria represents the main mechanism that produces stresses transferred to the Alps-Dinarides orogen and the Pannonian Basin. Certain effect 
on the mobility in the southeastern segments of the Pannonian Basin might be attributed to the influence of the remnants of the detached oceanic slab recognized in the vicinity of southeastern periphery of the basin. GPS measurements of the horizontal mobility in the southern part of the Pannonian Basin, conducted in the Vojvodina area of northern Serbia, show that variable magnitudes of displacement of the crustal segments, with minimum values in the western parts and gradually increasing towards east. Furthermore, from the neotectonic investigations it can be inferred that horizontal mobility of the crustal segments in the southern Pannonian domain is highly dependent on the presence of inherited regional and local tectonic structures. Reactivated in the present-day compressional regime, these structures enable tectonic transfer of crustal blocks, with the movement patterns that predominantly match regional strain field. Active tectonic role predominantly show the reactivated structures developed during the Miocene extensional evolution of the basin. In the western and central segments these are the faults oriented in the E-W direction, while in the eastern parts the N-S oriented structures prevail.

Satellite positioning on the passive geodetic networks has high importance from the point of view of the accuracy in determining significant displacements of the stabilized points in the crust. The strain tensor parameters are calculated within the framework of every triangle on the basis of the geodetic network division into final elements (triangles) which is succeeded by an interpolation within a regular network of points. The applied method is carried to estimate the strain accumulation of geodetic network located in the southern Pannonian basin (Vojvodina area) in roughly ten-year time interval. Albeit these geodetic measurements do not have their exclusive application in geodynamic investigations, for sure they offer powerful tools that help understanding most recent activities in the Earth's crust.

Hence, the tendency should be that the present study should continue and also include the third measuring campaign using GPS/GNSS statics. Subsequently, a general kinematic deformational model should be developed in order to obtain more comprehensive conclusions concerning regional crustal motions. As additional support to the measurements on the passive geodetic network that provides high spatial resolution, further investigations should also include a network of active permanent stations, since these would provide higher temporal resolution.

Acknowledgments. The authors express their gratitude to both anonymous reviewers for comments and suggestions made, which was significant for improving the quality of this manuscript. This study was partly supported by the Ministry of Education, Science and Technological Development of the Republic of Serbia (Projects Nos. 176015, 176019, and 
III42012). The authors are also grateful to the Republic Geodetic Authority of Serbia, for putting at their disposal the realized GPS measurements over the passive reference network SREF, which were used for the purposes of the present study.

\section{References}

Ambrožič, T. (2004), Deformacijska analiza po postopku Karlsruhe, Geodetski Vestnik 48, 3, 315-331, DOI: 10.15292/geodetski-vestnik.2013.03.479-497.

Anderson, H., and J. Jackson (1987), Active tectonics of the Adriatic region, Geophys. J. Roy. Astron. Soc. 91, 3, 937-983, DOI: 10.1111/j.1365-246X. 1987.tb01675.x.

Araszkiewicz, A., and M. Jarosiński (2013), Reliability of calculation of the lithosphere deformations in tectonically stable area of Poland based on the GPS measurements. In: Geophysical Research Abstracts, EGU General Assembly 2013, Vol. 15, EGU2013-4359.

Bada, G. (1999), Cenozoic stress field evolution in the Pannonian basin and surrounding orogens, Inferences from kinematic indicators and finite element stress modelling, Ph.D. Thesis, Vrije Universiteit, Amsterdam, 204 pp.

Bada, G., S. Cloetingh, P. Gerner, and F. Horváth (1998), Sources of recent tectonic stress in the Pannonian region: inferences from finite element modelling, Geophys J. Int. 134, 1 87-101, DOI: 10.1046/j.1365-246x.1998.00545.x.

Bada, G., F. Horváth, P. Dovenyi, P. Szafian, G. Windhoffer, and S. Cloetingh (2007), Present-day stress field and tectonic inversion in the Pannonian basin, Glob, Planet. Change 58, 1-4, 165-180, DOI: 10.1016/j.gloplacha. 2007.01.007.

Bennett, R.A., S. Hreinsdóttir, G. Buble, T. Bašić, Ž. Bačić, M. Marjanović, G. Casale, A. Gendaszek, and D. Cowan (2008), Eocene to present subduction of southern Adria mantle lithosphere beneath the Dinarides, Geology 36, 1, 3-6.

Biagi, L., and A. Dermanis (2006), The treatment of time-continuous GPS observations for the determination of regional deformation parameters. In: F. Sanso and A.J. Gil (eds.), Geodetic Deformation Monitoring: From Geophysical To Geodetic Roles, IAG Symposia, Vol. 131, 83-94, Springer, Berlin.

Bogusz, J., and M. Figurski (2012), GPS-derived height changes in diurnal and subdiurnal timescales, Acta Geophys. 60, 2, 295-317, DOI: 10.2478/s11600011-0074-5.

Bogusz, J., A. Klos, M. Figurski, M. Jarosinski, and B. Kontny (2013), Investigation of the reliability of local strain analysis by means of the triangle modelling, 
Acta Geodyn. Geomater. 10, 3, 171, 293-305, DOI: 10.13168/AGG.2013. 0029.

Cacoń, S., O. Švábenský, B. Kontny, J. Wiegel, O. Jarmoz, K. Ćmielewski, J. Bosy, J. Kaplon, and R. Machotka (2004), Deformation analysis of the upper part of the Earth crust in the Snieznik massif (Polish and Czech sides between 1993 and 2003), Acta Geodyn. Geomater. 1, 3, 135, 59-67.

Caspary, W.F. (2000), Concepts of Networks and Deformation Analysis, 3rd corr. ed., University of New South Wales.

Cloetingh, S., and E. Burov (2011), Lithospheric folding and sedimentary basin evolution: a review and analysis of formation mechanisms, Basin Res. 23, 3, 257-290, DOI: $10.1111 / \mathrm{j} .1365-2117.2010 .00490 . x$.

Cloetingh, S., L. Matenco, G. Bada, C. Dinu, and V. Mocanu (2005), The evolution of the Carpathians-Pannonian system: Interaction between neotectonics, deep structure, polyphase orogeny sedimentary basins in a source to sink natural laboratory, Tectonophysics 410, 1-4, 1-14, DOI: 10.1016/j.tecto. 2005.08.014.

Cloetingh, S., G. Bada, L. Matenco, A. Lankreijer, F. Horváth, and C. Dinu (2006), Modes of basin (de)formation, lithospheric strength and vertical motions in the Pannonian-Carpathian system: inferences from thermo-mechanical modelling, Geol. Soc. London Mem. 32, 207-221, DOI: 10.1144/GSL. MEM.2006.032.01.12.

Csontos, L. (1995), Tertiary tectonic evolution of the Intra-Carpathian area: a review, Acta Vulcan. 7, 1-13.

Dermanis, A., and E. Livieratos (1983), Applications of deformation analysis in geodesy and geodynamics, Rev. Geophys. Space Phys. 21, 1, 41-50, DOI: 10.1029/RG021i001p00041.

Frisch, W., J. Kuhlemann, I. Dunkl, and A. Brügel (1998), Palinspastic reconstruction and topographic evolution of the Eastern Alps during late Tertiary tectonic extrusion, Tectonophysics 297, 1-4, 1-15, DOI: 10.1016/S00401951(98)00160-7.

Gerner, P., G. Bada, P. Dővényi, B. Müller, M.C. Onescu, S. Cloetingh, and F. Horváth (1999), Recent tectonic stress and crustal deformation in and around the Pannonian basin: data and models, Geol. Soc. Lond. Spec. Publ. 156, 269-294, DOI: 10.1144/GSL.SP.1999.156.01.14.

Grenerczy, G., and A. Kenyeres (2006), Crustal deformations between Adria and the European platform from space geodesy. In: N. Pinter, G. Gyula, J. Weber, S. Stein, and D. Medak (eds.), The Adria Microplate: GPS Geodesy, Tectonics and Hazards, NATO Science Series: IV. Earth and Environmental Sciences, Vol. 61, Springer, 321-334, DOI: 10.1007/1-4020-4235-3_22.

Grenerczy, G., G. Sella, S. Stein, and A. Kenyeres (2005), Tectonic implications of the GPS velocity field in the northern Adriatic region, Geophys. Res. Lett. 32, 16, L16311, DOI: 10.1029/2005GL022947. 
Heck, B. (1983), Das Analyseverfahren des geodätishen Instituts der Universität Karlsruhe Stand 1983, Deformationsanalysen '83, Schriftenreihe HSBw, Heft 9, München, (in German).

Horváth, F. (1993), Towards a mechanical model for the formation of the Pannonian basin, Tectonophysics 226, 1-4, 333-357, DOI: 10.1016/0040-1951(93) 90126-5.

Horváth, F., and S.A.P.L. Cloetingh (1996), Stress-induced late-stage subsidence anomalies in the Pannonian basin, Tectonophysics 266, 1-4, 287-300, DOI: 10.1016/S0040-1951(96)00194-1.

Horváth, F., and J. Rumpler (1984), The Pannonian basement: extension and subsidence of an Alpine orogen, Acta Geol. Hung. 27, 229-235.

Horváth, F., G. Bada, P. Szafian, G. Tari, A. Adam, and S. Cloetingh (2006), Formation and deformation of the Pannonian Basin: Constraints from observational data, Memoirs 32, 1, 191-206, DOI: 10.1144/GSL.MEM.2006.032. 01.11 .

Jarosiński, M. (2012), Compressive deformations and stress propagation in intracontinental lithosphere: finite element modeling along the DinaridesEast European Craton profile, Tectonophysics 526-529, 24-41, DOI: 10.1016/ j.tecto.2011.07.014.

Jarosiński, M., F. Beekman, G. Bada, and S. Cloetingh (2006), Redistribution of recent collision push and ridge push in Central Europe: insights from FEM modelling, Geophys. J. Int. 167, 2, 860-880, DOI: 10.1111/j.1365-246X. 2006.02979.x.

Jarosiński, M., F. Beekman, L. Matenco, S. Cloetingh (2011), Mechanics of basin inversion: Finite element modelling of the Pannonian Basin System, Tectonophysics 502, 1-2, 121-145, DOI: 10.1016/j.tecto.2009.09.015.

Magyar, I., A. Fogarasi, G. Vakarcs, L. Buko, and G. Tari (2006), The largest hydrocarbon field discovered to date in Hungary: Algyő. In: J. Golonka and F.J. Picha (eds.), The Carpathians and Their Foreland: Geology and Hydrocarbon Resources, AAPG Memoirs, Vol. 84, 619-632, DOI: 10.1306/ 985734M843142.

Marović, M., I. Djoković, L. Pešić, S. Radovanović, M. Toljić, and N. Gerzina (2002), Neotectonics and seismicity of the southern margin of the Pannonian basin in Serbia, EGU Stephan Mueller Spec. Publ. Ser. 3, 277295.

Marović, M., M. Toljić, Lj. Rundić, and J. Milivojević (2007), Neoalpine tectonics of Serbia, Serbian Geological Society, Ser. Monographie, Belgrade, 87 pp. and map.

Martin, M., F. Wenzel, and CALIXTO Working Group (2006), High-resolution teleseismic body wave tomography beneath SE-Romania - II. Imaging of a slab detachment scenario, Geophys. J. Int. 164, 3 579-595, DOI: 10.1111/ j.1365-246X.2006.02884.x. 
Matenco, L., and D. Radivojević (2012), On the formation and evolution of the Pannonian Basin: constraints derived from the structure of the junction area between the Carpathians and Dinarides, Tectonics 31, 6, TC6007, DOI: 10.1029/2012TC003206.

Mihailović, K., and I. Aleksić (1994), Deformaciona Analiza Geodetskih Mreža, Gradjevinski Fakultet, Institut za Geodeziju, Beograd.

Mihailović, K., and I. Aleksić (2008), Koncepti Mreža u Geodetskom Premeru, Geokarta, Beograd.

Pamić, J. (2002), The Sava-Vardar Zone of the Dinarides and Hellenides versus the Vardar Ocean, Eclogae Geol. Helv. 94, 1-15.

Schmid, S.M., D. Bernoulli, B. Fügenschuh, L. Matenco, S. Schefer, R. Schuster, M. Tischler, and K. Ustaszewski (2008), The Alpine-Carpathian-Dinaridic orogenic system: correlation and evolution of tectonic units, Swiss J. Geosci. 101, 1, 139-183, DOI: 10.1007/s00015-008-1247-3.

Stegena, L., B. Géczy, and F. Horváth (1975), Late Cenozoic evolution of the Pannonian Basin, Tectonophysics 26, 1-2, 71-90, DOI: 10.1016/00401951(75) 90114-6.

Straub, Ch.S. (1996), Recent crustal deformation and strain in the Marmara Sea region, NW Anatolia Inferred from GPS Measurements, Ph.D. Thesis, ETH, Zurich.

Szafian, P., F. Horváth, and S. Cloetingh (1997), Gravity constraints on the crustal structure and slab evolution along a transcarpathian transect, Tectonophysics 272, 2-4, 233-247, DOI: 10.1016/S0040-1951(96)00260-0.

Szostak-Chrzanowski, A., W. Prószyński, and W. Gambin (2006), Continuum mechanics as a support for deformation monitoring, analysis and intrpretation, In: H. Kahmen and A. Chrzanowski (eds.), Proc. 3rd IAG / 12th FIG Symposium, 22-24 May 2006, Baden.

Talich, M. (2007), Geometrical analysis of deformation measurement using continuum mechanics by web application. In: FIG Working Week, 13-17 May 2007, Hong Kong SAR, China.

Talich, M. (2008), Practical advantages of using the mechanics of continuum to analyse deformations obtained from geodetic survey. In: Measuring the Changes - joint symposia of 13th FIG Int. Symp. on Deformation Measurements and Analysis and 4th IAG Symp. on Geodesy for Geotechnical and Structural Engineering, LNEC, 12-15 May, Lisbon, Portugal, available from: http://www.fig.net/commission6/lisbon_2008/papers/pas07/pas07_ 03_talich_mc056.pdf.

Talich, M. (2012), Creation of strain maps from velocity field of deformation by online tools. In: Space Geodesy and Earth System, 18-21 August 2012, Shanghai, China.

Talich, M., and J. Havrlant (2008), Application of deformation analysis and its new possibilities. In: Measuring the Changes - joint symposia of 13th FIG Int. Symp. on Deformation Measurements and Analysis and 4th IAG Symp. on 
Geodesy for Geotechnical and Structural Engineering, LNEC, 12-15 May, Lisbon, Portugal, available from: http://www.fig.net/commission6/lisbon 2008/papers/pst02/pst02_05_talich_mc057.pdf.

Tesauro, M., C. Hollenstein, R. Egli, A. Geiger, and H.G. Kahle (2006), Analysis of central western Europe deformation using GPS and seismic data, $J$. Geodyn. 42, 4-5, 194-209, DOI: 10.1016/j.jog.2006.08.001.

Toljić, M., L. Matenco, M.N. Ducea, U. Stojadinović, J. Milivojević, and N. Đerić (2013), The evolution of a key segment in the Europe-Adria collision: The Fruška Gora of northern Serbia, Global Planet Change 103, 39-62, DOI: 10.1016/j.gloplacha.2012.10.009.

Tóth, L., P. Mónus, T. Zsíros, and M. Kiszely (2002), Seismicity in the Pannonian Region - earthquake data, EGU Stephan Mueller Spec. Publ. Ser. 3, 9-28.

Vaniček, P., and J.E. Krakiwsky (1982), Geodesy, the Concepts, Elsevier Science B.V., Amsterdam.

Webster, R., and M.A. Oliver (2007), Geostatistics for Enviromental Scientist, Wiley \& Son, Ltd.

Welsch, W.M. (1983), Finite elements analysis of strain patterns from geodetic observations across a plate margin, Tectonophysics 97, 1-4, 57-71, DOI: 10.1016/0040-1951(83)90125-7.

Received 18 August 2015

Received in revised form 23 December 2015

Accepted 8 February 2016 